(c) American Dairy Science Association, 2004.

\title{
Components Detected by Means of Solid-Phase Microextraction and Gas Chromatography/Mass Spectrometry in the Headspace of Artisan Fresh Goat Cheese Smoked by Traditional Methods
}

\author{
M. D. Guillén ${ }^{1}$, M. L. Ibargoitia ${ }^{1}$, P. Sopelana ${ }^{1}$, G. Palencia ${ }^{1}$, and M. Fresno ${ }^{2}$ \\ ${ }^{1}$ Tecnología de Alimentos, Facultad de Farmacia, \\ Universidad del País Vasco, Paseo de la Universidad 7, \\ 01006 Vitoria, Spain \\ ${ }^{2}$ Instituto Canario de Investigaciones Agrarias, \\ La Laguna, Santa Cruz de Tenerife, Spain
}

\begin{abstract}
The study of the headspace components of fresh smoked goat cheese, was carried out by means of solidphase microextraction using a polyacrylate fiber followed by gas chromatography/mass spectrometry. The samples studied were six artisan Palmero cheeses manufactured following traditional methods and smoked using pine needles. The cheese regions studied were exterior, interior, and a cross section. In total, more than 320 components were detected, the exterior region being the richest in components, among which were acids, alcohols, esters, hydrocarbons, aldehydes, ketones, furan and pyran derivatives, terpenes and sesquiterpenes, nitrogen derivatives, phenol, guaiacol and syringol derivatives, ethers, and others. In addition to typical cheese components, typical smoke components were also detected; these latter were present especially in the headspace of the exterior region and only those in significant concentrations in the exterior region were also detected in the interior. The main components were acids and phenolic derivatives. These latter compounds play an important role in the flavor of this cheese, and their relative proportions together with the presence of specific smoke components derived from pine leaves may be considered of interest in order to distinguish this cheese from others smoked with different vegetable matter.
\end{abstract}

(Key words: pine leaves, smoked fresh goat cheese, headspace components, solid-phase microextraction)

Abbreviation key: GC/MS = gas chromatography/ mass spectrometry, SPME = solid-phase microextraction.

Received April 3, 2003.

Accepted May 22, 2003.

Corresponding author: M. D. Guillen; e-mail: knpgulod@vf.ehu.es.

\section{INTRODUCTION}

The volatile compounds of cheese, known to be important in cheese flavor, have been reported for many different types of cheese (Liebich et al., 1970a, 1970b; Sloot and Harkes, 1975; Parliament et al., 1982; Martelli, 1989; Martinez-Castro et al., 1991; Barbieri et al., 1994; Sabio and Vidal-Aragón, 1996; Muir et al., 1997; Kubícková and Grosch, 1997; Moio and Addeo, 1998; Moio et al., 2000; Rychlik and Bosset, 2001). Recently, solid-phase microextraction (SPME) followed by gas chromatography/mass spectrometry (GC/MS) has been shown useful for determination of volatile compounds in cheese (Chin et al., 1996; Jaillais et al., 1999; Dufour et al., 2001; Watkins et al., 2002; Lee et al., 2003).

In this paper, the study of the headspace of artisan Palmero cheeses smoked using pine needles was investigated. The Palmero cheese is a fresh smoked cheese manufactured on the Isle of Palma (The Canary Islands), which constitutes an important part of this isle's economy. This is an artisan cheese, protected recently by the Denomination of Origin, which only can be made using milk from Palmera goats, by the milk producers themselves, following traditional methods passed down from generation to generation. This is one of the few cheeses that combine the two characteristics of fresh and of smoked cheese. It is made with unpasteurized milk, recently harvested, and kid rennet or authorized enzymes for coagulation, and then smoked following traditional practices. The smoking can be done by burning almond shells (Prunus dulcis), dry prickly pear (Opuntia ficus indica), or the wood or needles of canary pine (Pinus canariensis). This cheese has a cylindrical shape and flat sides, with average compositional characteristics: $17.5 \%$ protein, $35.1 \%$ lipids, and $48.5 \%$ dry extract. This kind of cheese has been produced since at least the Middle Ages. This cheese, due to its organoleptic properties, has great consumer acceptability; however, its volatile components have never been studied.

The study was carried out by means of static headspace generation and extraction of its components by 
means of SPME, followed by GC/MS for the subsequent study of the extract. This is a technique that respects the environment because it does not require the use of organic solvents. We aimed to 1) characterize the components of the headspace of this cheese, many of which are responsible for its flavor; 2) study of the diffusion degree of the smoke components into the cheese; 3) study of the differences between cheeses manufactured by different artisans; and 4) search for the presence of labeling substances or marker compounds related with the vegetable matter used for the smoking.

\section{MATERIALS AND METHODS}

\section{Samples}

The collection of samples comprised six artisan Palmero cheeses, named A1, A2, A3, A4, A5, and A6, manufactured by six different artisans of the Palma Isle on the same date in the first week of July 2001. All of them had been elaborated following the traditional methods previously mentioned and smoked using canary pine needles. Their chemical composition was determined by near infrared spectroscopy, with previous calibration of the equipment (Instalab 600) as usual (Adamopoulos et al., 2001); likewise, the $\mathrm{pH}$ was determined. Each cheese had a cylindrical shape and was divided in four similar pieces. Three were vacuum packed and kept frozen at $-40^{\circ} \mathrm{C}$ until study. From the fourth piece, three different samples were prepared: the interior of the cheese, the exterior region, and a thin cross section representative of the entire cheese, containing both exterior and interior parts. The samples were chopped, and approximately $1 \mathrm{~g}$ of the chopped sample was weighed into a 4-mL amber screw-top vial (Supelco, Bellefonte, PA), sealed with a hole cap polytetrafluoroethylene/silicone septum. Samples not immediately used were frozen at $-40^{\circ} \mathrm{C}$ until its study.

\section{Generation of the Headspace and Extraction of Its Components by SPME}

Vials containing $1 \mathrm{~g}$ of the cheese sample were introduced into a water bath maintained at $50^{\circ} \mathrm{C}$. After a period of sample equilibration ( $15 \mathrm{~min}$ ), the fiber was inserted into the headspace of the sample and was maintained for $60 \mathrm{~min}$. The fiber used was a fiber of polyacrylate (85- $\mu \mathrm{m}$ film thickness), acquired from $\mathrm{Su}-$ pelco. Previous experiments (Guillén and Errecalde, 2002) carried out in our laboratory on the study of the headspace components of other smoked foods using fibers of carboxen/polydimethylsiloxane, polydimethylsiloxane $(100-\mu \mathrm{m}$ film thickness) and polyacrylate (85$\mu \mathrm{m}$ film thickness) show that carboxen/polydimethylsiloxane fiber basically retains the most volatile compo- nents of the headspace in very high proportions; however, polyacrilate $(85-\mu \mathrm{m}$ film thickness) fiber retains components of a broader volatility range, and polydimethylsiloxane (100- $\mu \mathrm{m}$ film thickness) fiber has less retention ability of smoke components than polyacrylate (85- $\mu \mathrm{m}$ film thickness) fiber.

\section{GC/MS Study}

Fibers with the adsorbed compounds were injected into a Hewlett-Packard gas chromatograph model HP 6890 Series II equipped with a mass selective detector 5973 and a Hewlett-Packard Vectra XM series 4 computer operating with the ChemStation program. A fused-silica capillary column was used $(60 \mathrm{~m}$ length $\times$ $0.25 \mathrm{~mm}$ inside diameter $\times 0.25 \mu \mathrm{m}$ film thickness; from Hewlett-Packard, Palo Alto, CA), coated with a nonpolar stationary phase (HP-5MS, 5\% phenyl methyl siloxane). The operation conditions were as follows: the oven temperature was set initially at $45^{\circ} \mathrm{C}(0.50$-min hold), and then increased to $250^{\circ} \mathrm{C}$ at $4^{\circ} \mathrm{C} / \mathrm{min}$ (20-min hold); the temperatures of the ion source and the quadrupole mass analyzer were kept at 230 and $150^{\circ} \mathrm{C}$, respectively; helium was used as the carrier gas at a pressure of $16.5 \mathrm{psi}$; the injector and detector temperatures were held at 220 and $280^{\circ} \mathrm{C}$, respectively; and splitless mode was used for injection with a purge time of $5 \mathrm{~min}$. The fiber was maintained in the injection port for $10 \mathrm{~min}$. Mass spectra were recorded at an ionization energy of $70 \mathrm{eV}$. After the first desorption, the fiber was routinely desorbed for a second time to determine if the first desorption process was complete, in order to take the corresponding measures.

Many components were identified by using standards. Asterisked compounds in Table 1 were acquired commercially and used as standards for identification; in addition, 4-ethyl-octanoic acid was also used to discard its presence in the headspace of this cheese. Many other components were only tentatively identified. In this latter case, the retention times together with the mass spectra, and a greater than $85 \%$ match with mass spectra from a commercial library were taken as identification criteria (Wiley 138.L, Mass Spectral Database, Wiley 1990), as in previous studies (Guillén et al., 1995; Guillén and Ibargoitia, 1996). Due to the overlapping of the signal of many compounds, semi-quantification was based on arbitrary units of the total current ion or of the base specific peak ion area counts divided by $10^{5}$. Tables 2 and 3 give the average values obtained for some main components together with their average deviations and the ion used for the quantification in each case. 
Table 1. Detected compounds in different cheese regions together with an indication of their concentration.

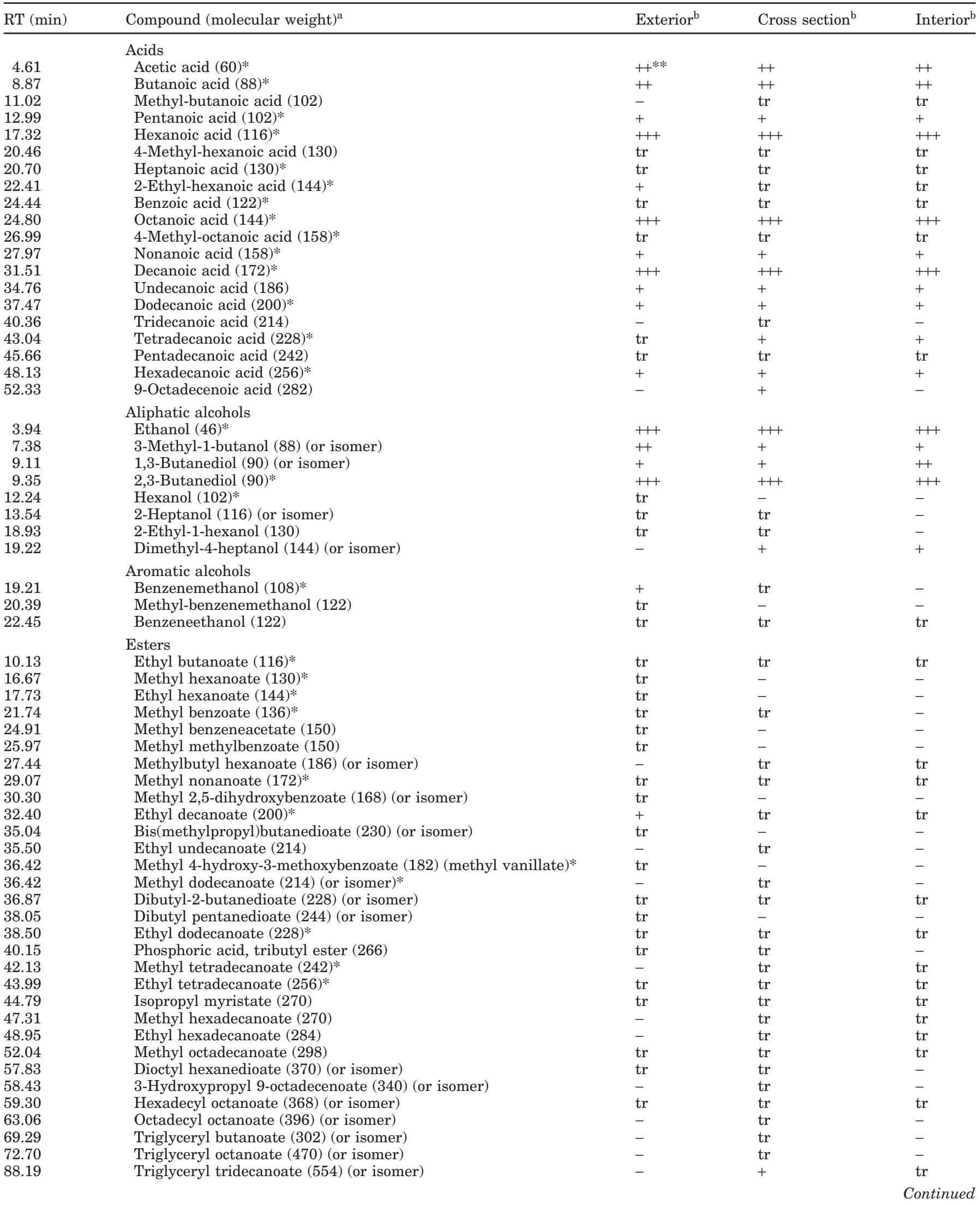


Table 1 (Continued). Detected compounds in different cheese regions together with an indication of their concentration.

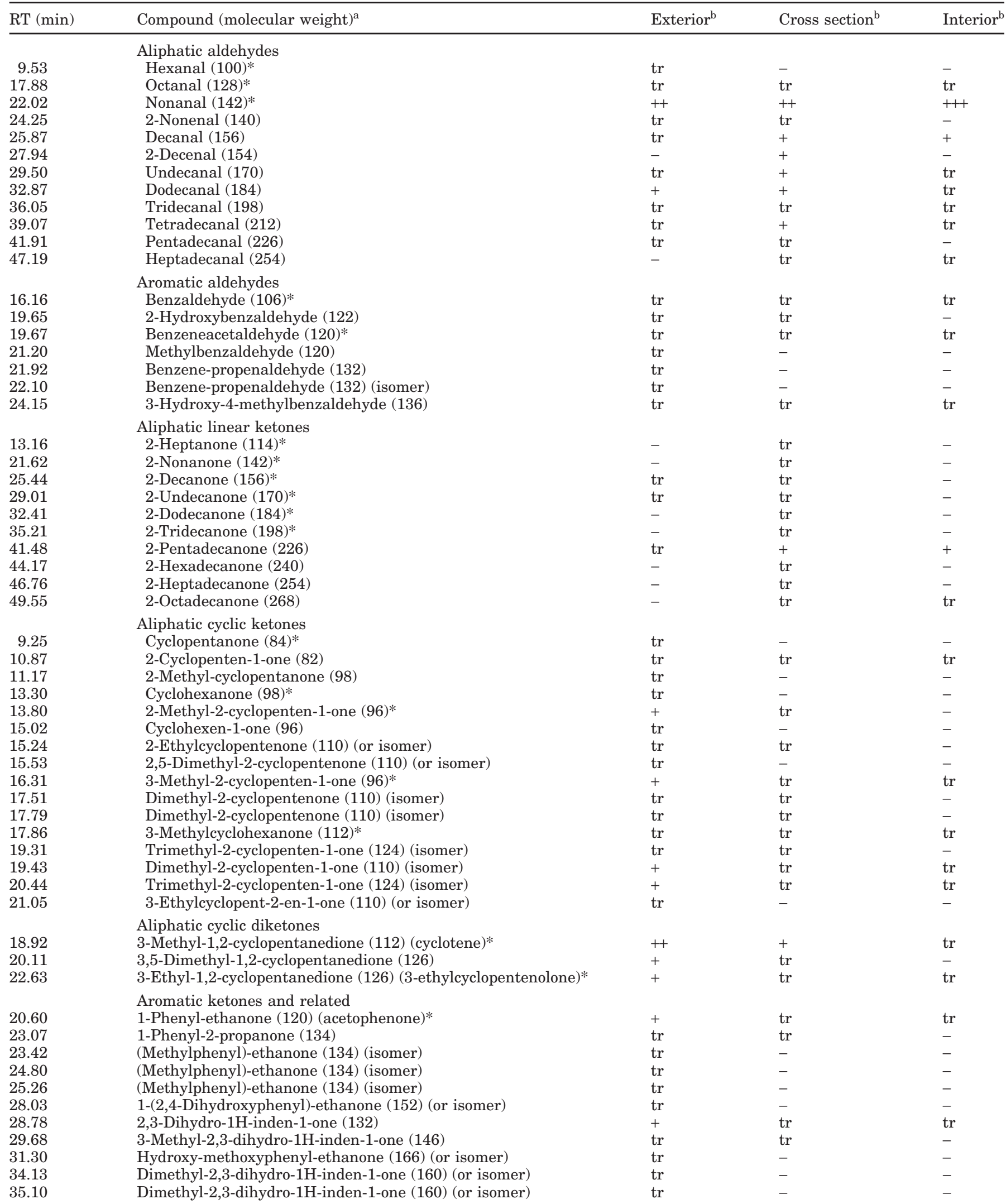


Table 1 (Continued). Detected compounds in different cheese regions together with an indication of their concentration.

\begin{tabular}{|c|c|c|c|c|}
\hline $\mathrm{RT}(\min )$ & Compound (molecular weight) ${ }^{\mathrm{a}}$ & Exterior $^{\mathrm{b}}$ & Cross section $^{b}$ & Interior $^{\mathrm{b}}$ \\
\hline 35.18 & Hydroxy-dimethoxyphenylethanone (196) (or isomer) & $\operatorname{tr}$ & - & - \\
\hline 35.52 & 1-(4-Hydroxy-3-methoxyphenyl)-ethanone (166) (acetovanillone)* & $\operatorname{tr}$ & - & - \\
\hline 36.60 & 2-Methyl-1,4-naphthalenedione (172) & $\operatorname{tr}$ & - & - \\
\hline 39.86 & Diphenyl methanone (182) & + & $\operatorname{tr}$ & $\operatorname{tr}$ \\
\hline 49.01 & 9,10 -Anthracenedione (208) & $\operatorname{tr}$ & $\operatorname{tr}$ & $\operatorname{tr}$ \\
\hline 50.75 & 1,4-Dimethyl-9,10-anthracenedione (236) & $\operatorname{tr}$ & $\operatorname{tr}$ & $\operatorname{tr}$ \\
\hline 21.89 & Undecane $(156)^{*}$ & - & $\operatorname{tr}$ & - \\
\hline 25.68 & Dodecane $(170)^{*}$ & - & $\operatorname{tr}$ & $\operatorname{tr}$ \\
\hline 28.23 & Tridecene (182) & - & $\operatorname{tr}$ & - \\
\hline 29.20 & Tridecane $(184)^{*}$ & - & $\operatorname{tr}$ & - \\
\hline 32.28 & Tetradecene (196) & $\operatorname{tr}$ & - & - \\
\hline 32.53 & Tetradecane $(198)^{*}$ & $\operatorname{tr}$ & $\operatorname{tr}$ & - \\
\hline 34.90 & 1-Pentadecene (210) (or isomer) & + & $\operatorname{tr}$ & $\operatorname{tr}$ \\
\hline 44.12 & Octadecane $(254) *$ & $\operatorname{tr}$ & $\operatorname{tr}$ & $\operatorname{tr}$ \\
\hline 45.18 & Neophytadiene $(278) *$ & - & $\operatorname{tr}$ & - \\
\hline 45.34 & $3,7,11,15$-Tetramethyl-2-hexadecene (280) (phytene) & $\operatorname{tr}$ & $\operatorname{tr}$ & $\operatorname{tr}$ \\
\hline 49.10 & Eicosene $(282)^{*}$ & $\operatorname{tr}$ & $\operatorname{tr}$ & $\operatorname{tr}$ \\
\hline 52.29 & Hydrocabon & $\operatorname{tr}$ & - & - \\
\hline 54.22 & Unsaturated hydrocarbon & $\operatorname{tr}$ & - & - \\
\hline 55.26 & Hydrocarbon & + & $\operatorname{tr}$ & $\operatorname{tr}$ \\
\hline 55.74 & Hydrocarbon & $\operatorname{tr}$ & - & - \\
\hline \multirow[t]{2}{*}{65.87} & Squalene $(410)^{*}$ & - & + & + \\
\hline & Monoaromatic hydrocarbons & & & \\
\hline 12.30 & Dimethylbenzene (106) (isomer) & $\operatorname{tr}$ & - & - \\
\hline 13.19 & Styrene $(104)^{*}$ & $\operatorname{tr}$ & - & - \\
\hline 13.31 & Dimethylbenzene (106) (isomer) & $\operatorname{tr}$ & - & - \\
\hline 24.15 & Methyl-1H-indene (130) (isomer) & $\operatorname{tr}$ & - & - \\
\hline 24.27 & Azulene (128) & $\operatorname{tr}$ & - & - \\
\hline 25.31 & Naphthalene $(128)^{*}$ & + & $\operatorname{tr}$ & - \\
\hline 27.45 & Decahydro-naphthalene (138) & $\operatorname{tr}$ & - & - \\
\hline 29.36 & 2-Methylnaphthalene $(142)^{*}$ & $\operatorname{tr}$ & $\operatorname{tr}$ & $\operatorname{tr}$ \\
\hline 29.93 & 1-Methylnaphthalene $(142)^{*}$ & $\operatorname{tr}$ & $\operatorname{tr}$ & - \\
\hline 30.46 & 2,3-Dihydro-trimethyl-1H-indene (160) (or isomer) & $\operatorname{tr}$ & - & - \\
\hline 30.99 & 2,3-Dihydro-trimethyl-1H-indene (160) (or isomer) & $\operatorname{tr}$ & - & - \\
\hline 32.16 & $1,1^{\prime}$-Biphenyl (154) & $\operatorname{tr}$ & $\operatorname{tr}$ & - \\
\hline 32.69 & Ethyl-naphthalene (156) & $\operatorname{tr}$ & - & - \\
\hline 33.38 & 2,3-Dihydro-trimethyl-1H-indene (160) (or isomer) & $\operatorname{tr}$ & $\operatorname{tr}$ & - \\
\hline 33.51 & Dimethyl-naphthalene (156) & $\operatorname{tr}$ & - & - \\
\hline 33.56 & 2,2'-Dimethyl-1,1'-biphenyl (182) (or isomer) & $\operatorname{tr}$ & - & - \\
\hline 33.65 & Dimethyl-naphthalene (156) & $\operatorname{tr}$ & - & - \\
\hline 33.73 & Tetrahydro-dimethyl-naphthalene (160) (or isomer) & $\operatorname{tr}$ & - & - \\
\hline 34.56 & Acenaphthylene $(152)^{*}$ & + & $\operatorname{tr}$ & - \\
\hline 38.63 & 9H-Fluorene (166) & $\operatorname{tr}$ & - & - \\
\hline 44.19 & Phenanthrene $(178)^{*}$ & $\operatorname{tr}$ & - & - \\
\hline & Furan and pyran derivatives & & & \\
\hline 11.05 & 2-Furancarboxaldehyde $(96)^{*}$ & + & $\operatorname{tr}$ & - \\
\hline 11.63 & 2 -Furanmethanol $(98)^{*}$ & ++ & + & $\operatorname{tr}$ \\
\hline 14.02 & 1-(2-Furanyl)-ethanone (110) (2-acetylfuran)* & + & - & $\operatorname{tr}$ \\
\hline
\end{tabular}


Table 1 (Continued). Detected compounds in different cheese regions together with an indication of their concentration.

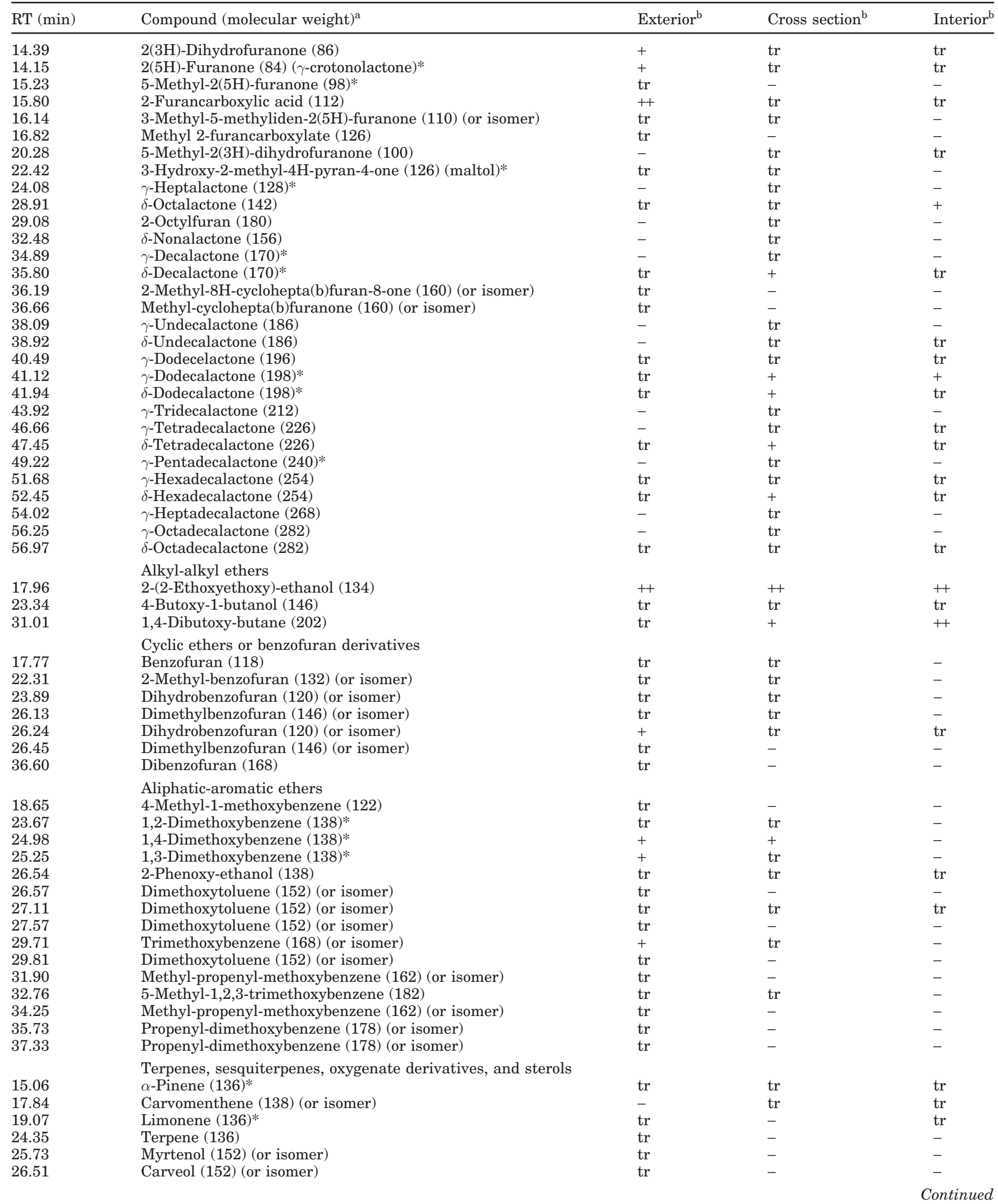


Table 1 (Continued). Detected compounds in different cheese regions together with an indication of their concentration.

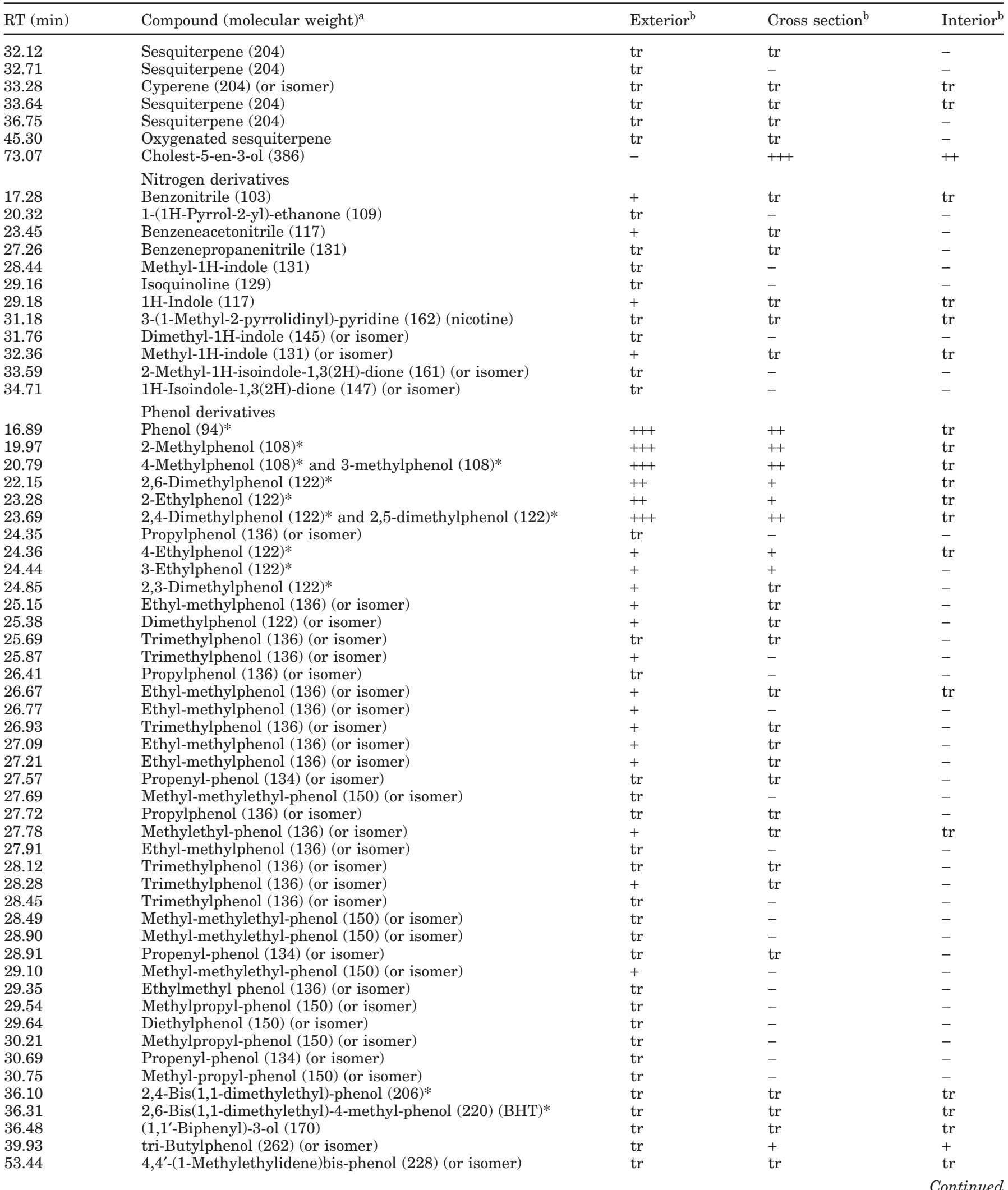


Table 1 (Continued). Detected compounds in different cheese regions together with an indication of their concentration.

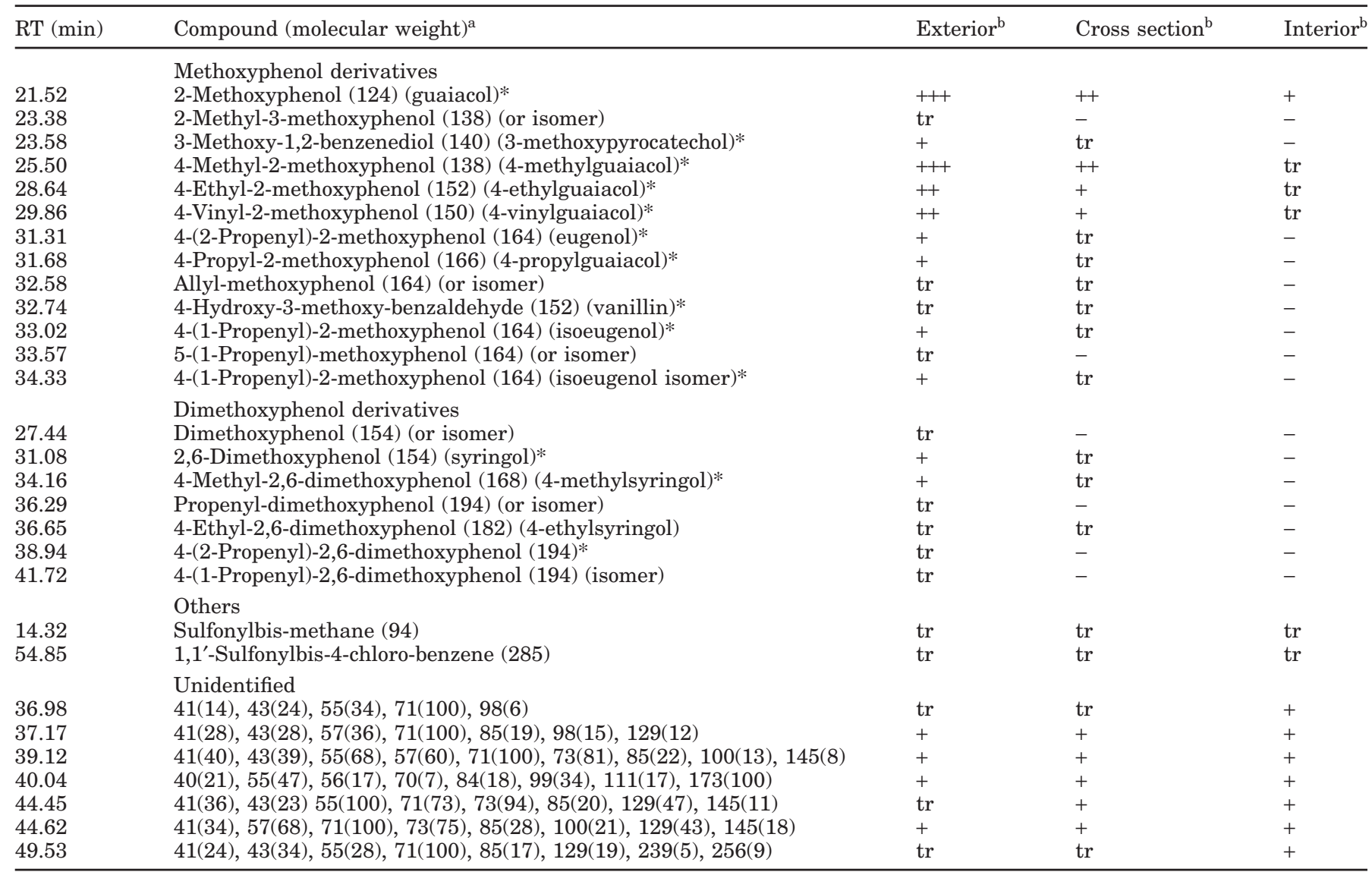

${ }^{a}$ Asterisked compounds were identified by standards.

${ }^{\mathrm{b}}$ Great number of area counts $=+++$; medium number of area counts $=++$; small number of area counts $=+$; very low number of area counts $=$ tr; not detected $=-$.

Table 2. Average concentrations (Con) of some components from the smoke in the headspace of the exterior cheese region, calculated from the A1, A2, A3, A5, and A6 samples, given in area counts of base peak ions $\left(\mathrm{I}_{\mathrm{BP}}\right)$ multiplied by $10^{-5}$, together with the average deviations.

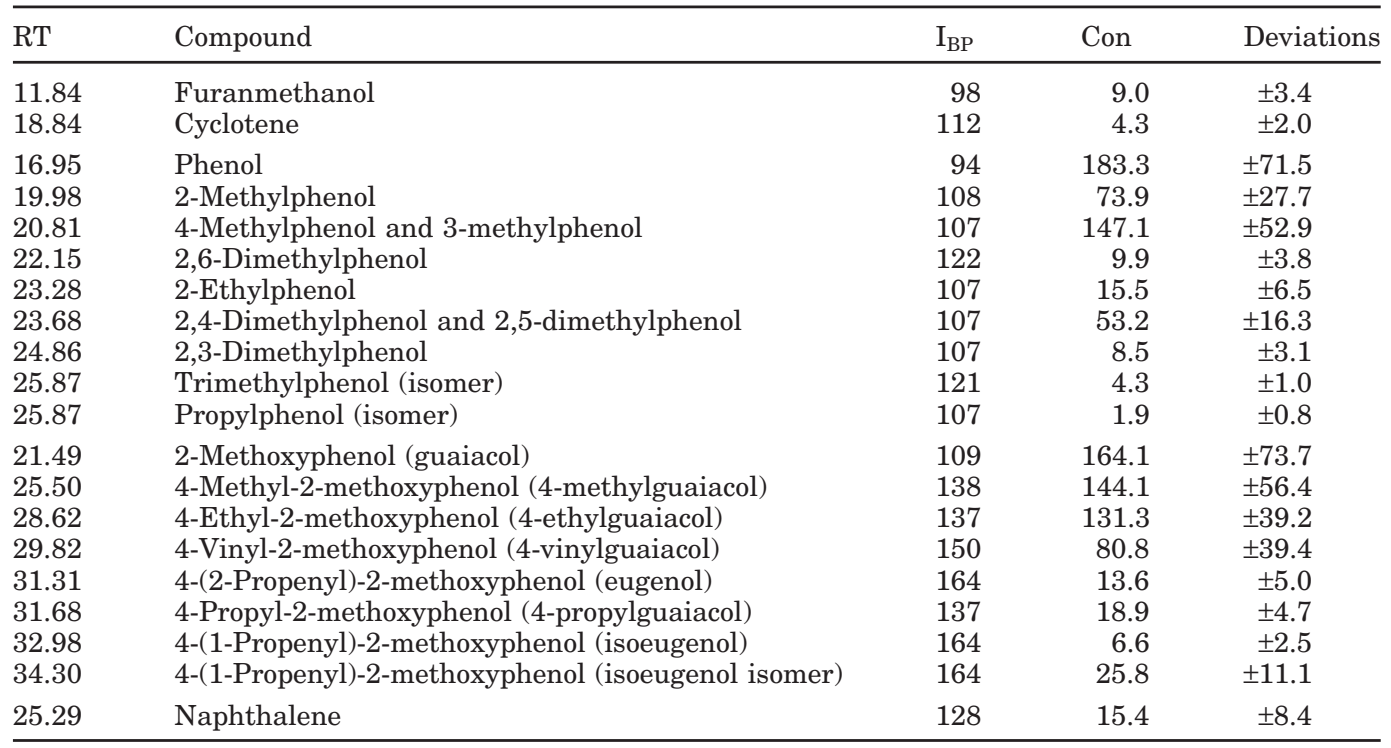


Table 3. Average concentrations (Con) of the acids in the headspace of the exterior cheese region, calculated from the A1, A3, A4, A5, and A6 samples, given in area counts of base peak ions ( $\left.\mathrm{I}_{\mathrm{BP}}\right)$ multiplied by $10^{-5}$, together with the average deviations.

\begin{tabular}{rlrrr}
\hline RT & Compound & $\mathrm{I}_{\mathrm{BP}}$ & Con & Deviations \\
\hline 9.45 & Butyric acid & 60 & 27.5 & \pm 16.9 \\
12.99 & Pentanoic acid & 60 & 1.2 & \pm 0.7 \\
17.77 & Hexanoic acid & 60 & 132.6 & \pm 67.5 \\
21.34 & Heptanoic acid & 60 & 4.7 & \pm 1.4 \\
22.65 & 2-Ethylhexanoic acid & 73 & 1.7 & \pm 1.5 \\
25.35 & Octanoic acid & 60 & 100.4 & \pm 37.6 \\
28.22 & Nonanoic acid & 60 & 3.4 & \pm 1.1 \\
32.04 & Decanoic acid & 60 & 94.3 & \pm 32.7 \\
34.76 & Undecanoic acid & 60 & 1.7 & \pm 1.5 \\
37.86 & Dodecanoic acid & 73 & 5.9 & \pm 3.4 \\
43.48 & Tetradecanoic acid & 73 & 3.5 & \pm 3.5 \\
45.82 & Pentadecanoic acid & & 0.6 & \pm 0.0 \\
\hline
\end{tabular}

\section{RESULTS AND DISCUSSION}

The six cheeses have very similar composition in terms of humidity $(45.64 \pm 1.06 \%)$, proteins $(20.65 \pm$ $1.05 \%)$, fat $(22.56 \pm 2.4 \%)$, and $\mathrm{pH}(5.77 \pm 0.23)$, in agreement with that indicated in the Origin Denomination regulation (BOE No. 218, 11/9/01). Table 1 gives the compounds detected in the exterior and interior regions of the cheese, as well as in a cross section that represents the whole cheese sample. Most of these compounds were detected in all samples studied; however, some of them were detected in only some samples. The number of detected compounds was very high (more than 320), and they have been grouped according to their nature: acids, alcohols, esters, hydrocarbons, aldehydes, ketones, furan and pyran derivatives, terpenes and sesquiterpenes, nitrogen derivatives, phenol, guaiacol and syringol derivatives, ethers, and others. The detected compounds show a broad range of molecular weights and volatilities. Taking into account the operating conditions of the experiments, the detection of compounds of very low volatility and very high molecular weight can only be explained by synergistic effects in the volatilization process.

Acids form the most important group by concentration, comprising 20 components, and in general coming from triglyceride lypolysis or hydrolysis, although other routes are also possible. Most are saturated linear acids with an even or uneven number of carbon atoms, the first being of a higher concentration than the second. Hexanoic, octanoic, and decanoic acids are the main components; this is consistent with their names: caproic (or capronic), caprylic, and capric (or caprinic) acids, respectively-all of them coming from the word capra or goat genus. Although linear acids are the main components of this cheese's headspace, they appear in lower concentrations than in other types of cheese studied in our laboratory (Guillén and Abascal, 2002). In different articles, the presence of the branched 4-methyl- and 4- ethyl-octanoic acids has been considered to be a distinctive characteristic of goat cheese (Salles et al., 2002); however, in this Palmero cheese, the main branched acids are 4-methyl and 2-ethylhexanoic acids, with 4methyloctanoic acid in very low proportions (even undetectable in some samples) and with 4-ethyloctanoic acid totally absent. This fact could be considered a distinctive characteristic of this goat cheese, attributable to the composition of the milk as a result of either the goat breed or the feed. In addition, benzoic and oleic acids have also been detected. The presence of low proportions of benzoic acid in cheese has been associated with bacterial growth, and its formation has been explained by two different processes: either from hippuric acid by fermentation or from benzaldehyde autoxidation (Overstrom et al., 1972; Sieber et al., 1995); this latter compound has also been detected in the headspace of this cheese (see Table 1, aldehydes group). It should be noted that not all methods previously cited to study cheese volatile components are able to isolate and detect acids.

Few alcohols have been detected, and only those with a small number of carbon atoms are seen in significant proportions. Among aliphatic alcohols, there are primary and secondary as well as linear or branched forms; all of these have been identified before as cheese components and can come from lactose, amino acids, or from acids through different processes (Molimard and Spinnler, 1996). The origin of the aromatic alcohols could be found in the smoke, although some of them, such as benzeneethanol are important to the flavor of several unsmoked cheeses (Rychlik and Bosset, 2001; Sorensen and Benfeldt, 2001; Valero et al., 2001).

The ester group contains 31 components, most of them with a single ester group, although compounds with two or three have also been detected. This group includes esters whose origin could be attributed to reactions between acids and alcohols, as well as triglycer- 
ides; the presence of these latter compounds, with large molecular weights and low volatility could only be explained by synergistic effects during headspace generation, as was commented above. In general, the concentration of esters is very low, the most significant being ethyl decanoate. Finally, it only remains to add that some aromatic esters derived from benzoic, methylbenzoic, and benzeneacetic acids have also been detected, together with methyl vanillate, a compound derived from vanillic acid, which is a typical smoke component (Guillén and Ibargoitia, 1998).

The group of aldehydes is formed by saturated and unsaturated aliphatic and aromatic aldehydes. Saturated, unsaturated aliphatic, and some aromatic aldehydes have been detected in the headspace of different unsmoked cheeses (Moio and Addeo, 1998; Thierry et al., 1999). The saturated aldehydes vary from 6 to 17 carbon atoms, with an even or uneven number of carbon atoms and can come from acids or from amino acids; the most significant are nonanal, decanal, undecanal, and dodecanal-especially the first. Only two unsaturated aldehydes have been detected. It should be noted that this type of aldehyde has not been detected in cheese very often. In addition, some aromatic aldehydes have also been detected. Some of them, such as benzaldehyde, hydroxy-benzaldehyde, and benzeneacetaldehyde (which has bitter, almond, fragrant, sweet, creamy, nutty, woody, balsamic notes), are common cheese components (Careri et al., 1994); however, others, such as vanillin, are typical smoke components (Guillén and Ibargoitia, 1998). It is probably for this reason that some of these have not been detected in the interior region.

Ketones are numerous (47 components). There is a subgroup of 10 methyl ketones, with between 7 and 18 carbon atoms, well-known cheese components whose formation has been attributed to $\beta$-oxidation of fatty acids; these ketones are seen in very low concentrations. There is also a subgroup of cyclic ketones, typical smoke components (Guillén and Ibargoitia, 1996); among these, the most significant are some methyl, dimethyl, and trimethyl cyclopentenones, which have diffused into the interior region. The cyclic diketones detected, with well-known nutty, burnt, brandy, coffee, caramel, and maple syrup notes (Maga, 1988), are the main ketones, and some have also been detected at trace levels in the interior of cheese. These compounds come from smoke (Maga, 1988). Finally, this group also includes an important number of aromatic ketones, most of them smoke components, explaining why they are almost exclusively found in the exterior region. It must be noted that only those ketones normally present in significant proportions in smoke (Guillén and Ibargoitia, 1996) have been detected in the interior of the cheese.
Hydrocarbons, in a great number and at very low concentrations, are also present in the headspace. Among these there are saturated and unsaturated aliphatic hydrocarbons, as well as mono- and poly-aromatic hydrocarbons. Linear saturated and unsaturated hydrocarbons, having from 9 to more than 18 carbon atoms, have been detected, as have branched hydrocarbons of very high molecular weight; the most significant is heptadecane. Linear saturated and unsaturated hydrocarbons have been detected in unsmoked cheeses (Larrayoz et al., 2001), although the saturated ones also are smoke components (Guillén and Ibargoitia, 1998). In addition, there are present three branched hydrocarbons: squalene, phytene, and neophytadiene; these have been previously detected in cheese (Banks et al., 1992; Dirinck and De Winne, 1999; Guillén and Abascal, 2002) and are present in many plants. If these plants form any part of the goat diet, they could be the cause of the presence of the aforementioned hydrocarbons in this cheese. The origin of the monoaromatic hydrocarbons detected is difficult to establish because they are also smoke constituents, and some of them, such as styrene and other alkylbenzene hydrocarbons, have also been detected in unsmoked cheese (Guichard et al., 1987; Bosset and Gauch, 1993; Bosset et al., 1997). The polyaromatic hydrocarbons detected, all of them of low molecular weight, probably are from the smoke, although some of them have also been detected in unsmoked cheese (Guichard et al., 1987; MartinezCastro et al., 1991; Careri et al., 1994; Jaillais et al., 1999). It should be noted that aliphatic hydrocarbons have been detected both in the exterior and interior region of cheese; however, aromatic hydrocarbons generally have been found in the exterior; this fact could indicate a different origin for both kinds of hydrocarbons.

The furan and pyran derivatives constitute a very large group, with 33 components. Among these, all those of low molecular weight (from 2-furancarboxaldehyde to maltol) coming from the smoke (Guillén and Ibargoitia, 1996) are found not only in the exterior but also in the interior region, although in a higher concentration in the first vs. the second region, as expected. Most of these compounds give pleasant flavors, such as caramel, sweet, toasted malt, bread-like, spicy, warm, and butterscotch (Maga, 1988). In addition to these components, a great number of $\gamma$ - and $\delta$-lactones, most of them in very low concentrations, have been detected; among these, $\delta$-decalactone, $\delta$-dodecalactone, $\delta$-tetradecalactone, and $\delta$-hexadecalactone are seen in higher proportions. These compounds, probably resulting from oxidation of fatty acids and subsequent cyclation of the formed hydroxyacids, are well known cheese components, although the number of lactones usually detected 
in cheese is lower than that found here; their flavor has been described as pleasant, buttery, and fruity.

Ethers constitute another group of components. This group contains some alkyl-alkyl ethers in significant proportions, most of which also have an alcohol group, which are distributed similarly in both the interior and exterior cheese regions. Some authors have previously described the presence of some of these components in cheese (Moio et al., 1993; Careri et al., 1994; Lecanu et al., 2002). Within this group, a subgroup of compounds tentatively identified as benzofuran derivatives has also been included, together with another of alkyl-aryl ethers; both kinds of compounds, which are basically present only in the exterior region, are well known smoke components (Guillén and Ibargoitia, 1998).

The presence of terpenes and sesquiterpenes in pine needles, as well as of some of their oxygen derivatives, is well documented (Lapp and Von, 1982; Papadopoulou and Koukos, 1996; Marculescu and Gleizes, 2002). For this reason, their presence in this cheese could be attributed to the smoke used in manufacture; however, in other cheeses, their presence has been attributed to the animal feed (Dumont et al., 1981; Guichard et al., 1987; Bosset et al., 1994) or to the activity of Penicillium caseifulvum and of $P$. camemberti fungus (Larsen, 1999). Their concentration is very low and all of them have interesting organoleptic properties.

In addition, a group of nitrogen derivatives, including nitrile and indole derivatives, has also been detected. Some of these, known smoke components, are found in higher proportions in the exterior than in the interior region, so their origin could be attributed to the smoke. However, benzonitrile (Barbieri et al., 1994; Careri et al., 1994; Sunesen et al., 2002), as well as some indole derivatives, has also been detected in unsmoked cheese and is considered to result from the activity of lactic acid bacteria on amino acids (Gao et al., 1997; Kemmer et al., 1997; Rychlik and Bosset, 2001; Valero et al. 2001; Tavaria et al., 2002). Nicotine has also been detected, both in the exterior and interior region, always at very low proportions; this compound has been previously described as a cheese component (Moio and Addeo, 1998; Guillén and Abascal, 2002).

The largest group of components is that of phenolic derivatives, constituted by phenol (43 components), methoxyphenol (13 components), and dimethoxyphenol (7 components) derivatives. All of them are well-known smoke components (Maga, 1988), and only those in significant concentrations in the exterior region have diffused into the interior, these being phenol, guaiacol, syringol, and some of their low-molecular-weight alkyl derivatives. The high number of phenol and low number of syringol derivatives is noteworthy. The flavor notes contributed by phenol derivatives are pungent and cre- solic, whereas those of guaiacol derivatives have been described as sweet, smoky, somewhat pungent, weak, phenolic, and woody, and those of syringol derivatives have been described as smoky, mild, heavy, and burnt (Kim et al., 1974; Maga, 1988).

Finally, a reduced number of other components of unknown origin (some of which are probably contaminants, such as sulfonylbis-methane and 1,1'-sulfonylbis-4-chloro-benzene, which are monomers of some polyesters) also have been detected at very low concentrations.

The contribution of the different compounds mentioned above to the Palmero cheese flavor is determined by the taste and odor threshold values of each of these compounds in this fresh cheese matrix.

As can be observed in Table 1, the headspace of the interior region of the Palmero cheese is poorer in volatile components than the exterior region because only those smoke components in significant concentrations in the exterior region, such as some cyclic ketones and diketones, some furan and pyran derivatives of low molecular weight, some phenol and guaiacol derivatives, as well as some alkyl-aryl ethers, diffuse through the cheese matrix and reach the interior region, although in very low concentrations. The slight diffusion of smoke components into the cheese matrix could be due to the short time between smoking and consumption of this cheese; it is likely that in smoked cheeses with a long period of ripening, this diffusion is greater. As could be expected, the headspace of the cross section contains more components than the interior region but less than the exterior region. This can also be observed in Figure 1 , which gives the total current ion chromatogram of the headspace components of the exterior, interior, and cross section of sample A4, which is the most smoked of all studied.

Smoke comprises a large number of components from cellulose, hemicellulose, and lignin pyrolysis, which have different functional groups, such as ketones, aldehydes, acids, ethers, hydrocarbons, carbohydrate derivatives, nitrogen derivatives, and phenol, guaiacol, syringol, and pyrocatechol derivatives (Guillén and Ibargoitia, 1996; Guillén and Manzanos, 1999; Guillén et al., 2001). Among these components, generally carbonyl and carboxyl derivatives together with carbohydrate derivatives are the major smoke components, whereas phenolic derivatives are found in smaller proportions. In the smoking process, the smoke components are deposited at random on the cheese surface. If smoke components do not react at all or do not interact very strongly with cheese components, both systems, smoke and smoked cheese, will contain the same components coming from wood pyrolysis and in similar proportions. 


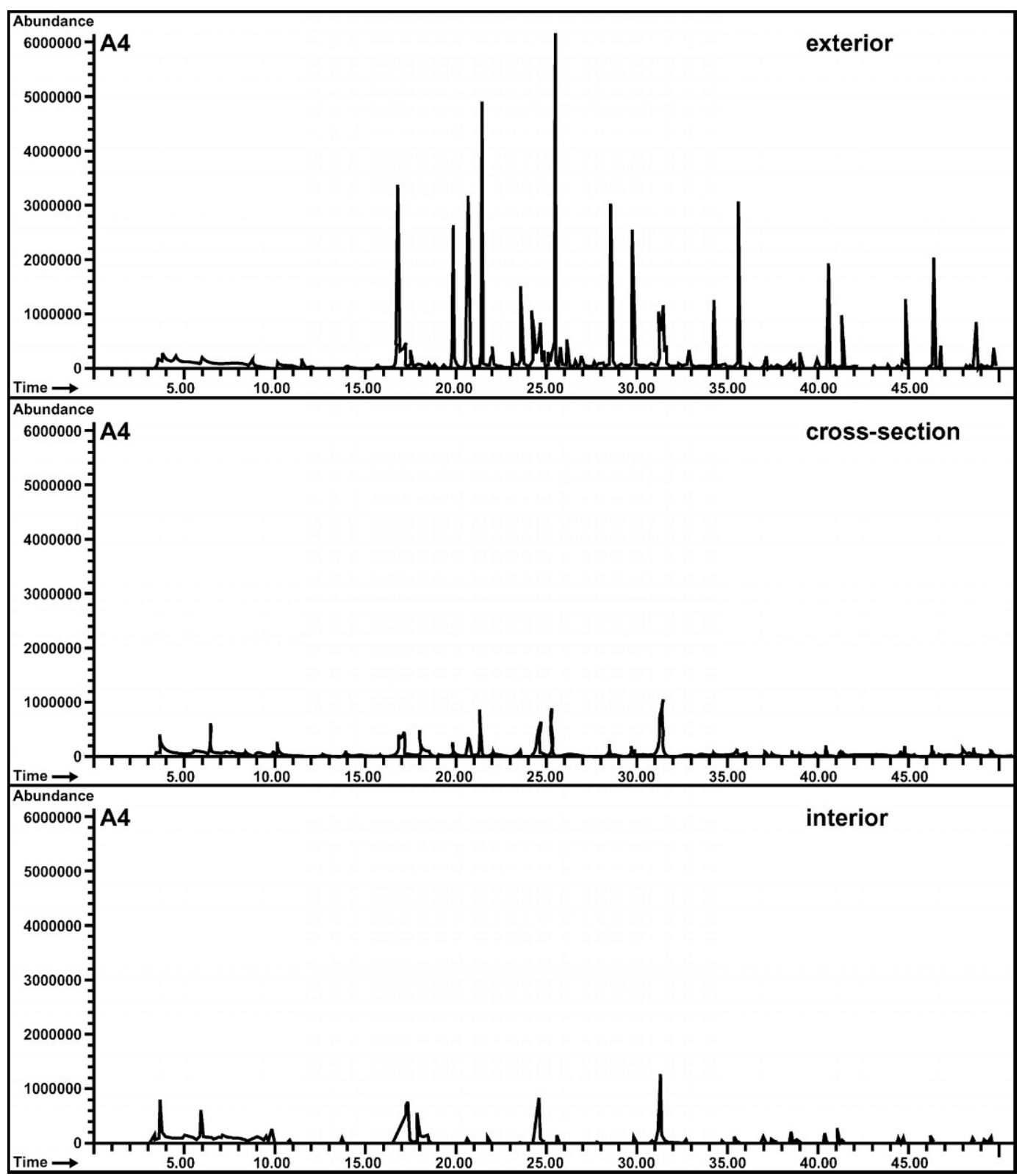

Figure 1. Total ion current chromatogram of the components of the headspace of the exterior, cross section, and interior regions of the A4 cheese sample.

In spite of carbonyl, furan, pyran, and other carbohydrate derivatives being found in higher proportions than phenolic derivatives in smoke (Maga, 1988; Guillén and Ibargoitia, 1996; Guillén and Manzanos, 1999), in the headspace of this smoked cheese, the opposite is true: that is to say the headspace contains proportions of carbonyl, furan, and pyran derivatives, and of phenolic derivatives, which are very different from those generally found in smoke. This could be due to some carbonyl derivatives reacting with amine cheese groups in reactions similar to those of Maillard, modifying the texture and the color of the cheese, or because carbonyl derivatives are strongly retained by cheese components. The high proportions of phenol derivatives in the headspace of this cheese could be due to the fact that these smoke components neither react nor interact very strongly with cheese components.

This Palmero cheese, as has been commented on above, is made by artisans and for this reason there is some variability among the headspace composition of the different samples studied. The differences found are related to the concentration of the components but 


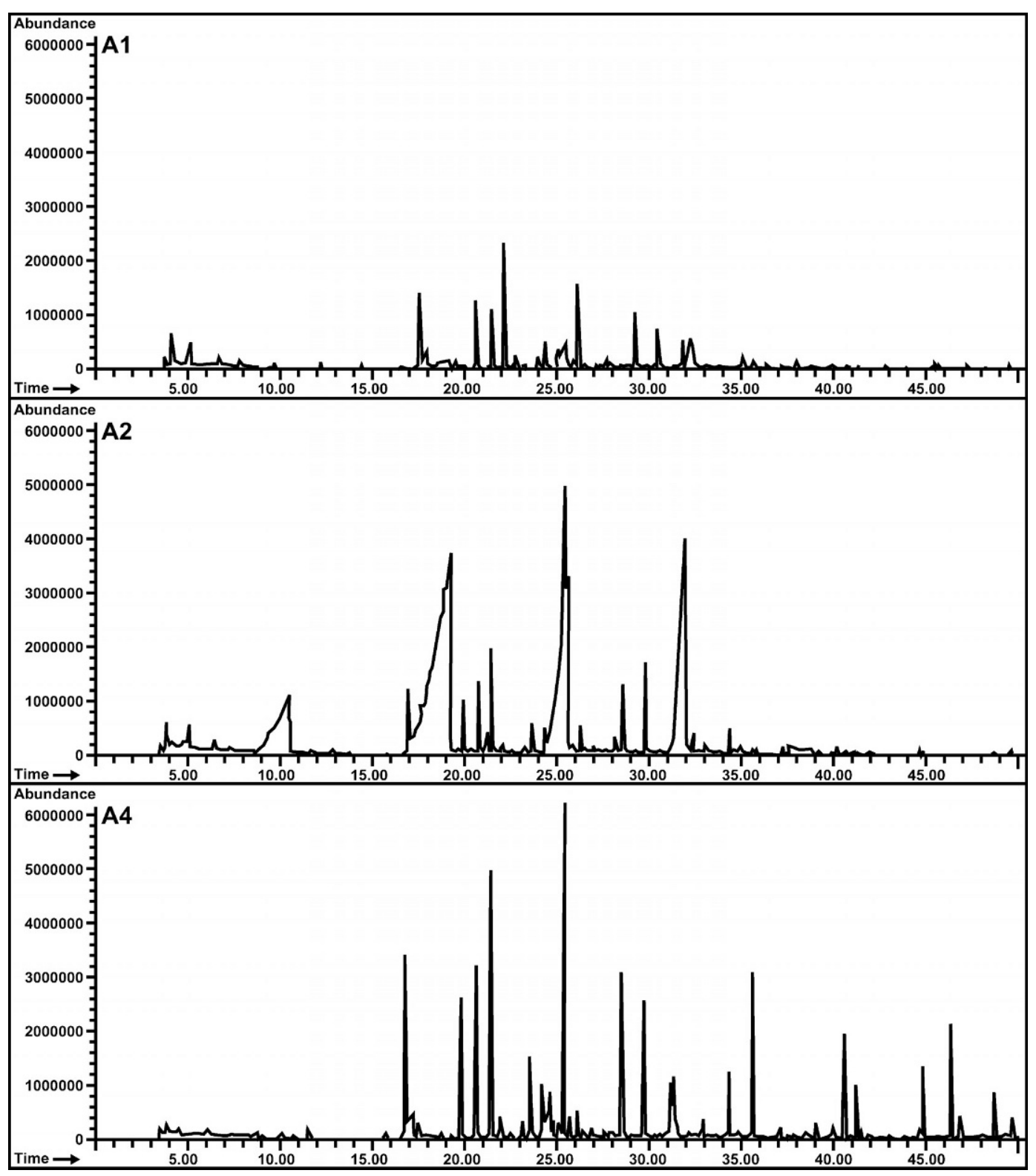

Figure 2. Total ion current chromatogram of the components of the headspace of the exterior region of the A1, A2, and A4 cheese samples.

not to their nature. The A2 and A4 samples contain concentrations in fatty acids and in smoke components respectively, which are much greater than those found in the other samples due to an accentuation of the lypolysis in the first case and of the smoking process in the second. Both are extreme cases. Figure 2 shows the total current ion chromatogram of the headspace of the exterior region of these two cited samples and of sample A1; it can be observed that in the headspace of the exterior region of sample A2, the hexanoic, octanoic, and decanoic acids predominate, whereas in the headspace of the exterior region of sample A4, the phenolic derivatives predominate (i.e., phenol and their methyl derivatives and guaiacol and their alkyl derivatives). However, in the headspace of the exterior region of sample A1, although smoke components are the main components, their abundance is much lower than in sample A4.

Table 2 shows the cheese headspace average concentrations in samples A1, A2, A3, A5, and A6, of some compounds known as typical smoke components (Maga, 1988), together with average deviations. These concentrations are given in area counts of the base peak ions of each compound multiplied by $10^{-5}$. Table 3 gives the 
Table 4. Abundance of some smoke components in the headspace of the exterior region of the different cheese samples expressed as percentage in relation to the total abundance of them.

\begin{tabular}{|c|c|c|c|c|c|c|c|c|}
\hline RT & Compound & Ion & A1 & $\mathrm{A} 2$ & A3 & A4 & A5 & A6 \\
\hline 11.84 & Furanmethanol & 98 & 0.9 & 0.9 & 0.5 & 0.5 & 0.7 & 1.1 \\
\hline 18.84 & Cyclotene & 112 & 0.6 & 0.3 & 0.3 & 0.4 & 0.3 & 0.4 \\
\hline 16.95 & Phenol & 94 & 19.5 & 17.9 & 14.9 & 16.7 & 12.7 & 16.9 \\
\hline 19.98 & 2-Methylphenol & 108 & 8.2 & 6.7 & 7.8 & 6.3 & 5.1 & 5.5 \\
\hline 20.81 & 4-Methylphenol and 3-methylphenol & 107 & 13.8 & 13.7 & 13.6 & 15.0 & 11.9 & 13.8 \\
\hline 22.15 & 2,6-Dimethylphenol & 122 & 1.1 & 0.9 & 1.1 & 0.8 & 0.7 & 0.6 \\
\hline 23.28 & 2-Ethylphenol & 107 & 2.0 & 1.3 & 1.7 & 1.1 & 0.9 & 1.1 \\
\hline 23.28 & 2,4-Dimethylphenol and 2,5-dimethylphenol & 107 & 5.7 & 4.6 & 6.6 & 4.8 & 3.5 & 4.6 \\
\hline 23.68 & 2,3-Dimethylphenol & 107 & 1.1 & 0.6 & 1.1 & 0.6 & 0.5 & 0.7 \\
\hline 25.50 & Trimethylphenol (or isomer) & 121 & 0.4 & 0.4 & 0.6 & 0.4 & 0.3 & 0.4 \\
\hline 25.87 & Propylphenol (or isomer) & 107 & 0.3 & 0.2 & 0.2 & 0.1 & 0.1 & 0.2 \\
\hline 21.49 & 2-Methoxyphenol (guaiacol) & 109 & 16.6 & 13.6 & 12.0 & 15.0 & 16.0 & 12.4 \\
\hline 25.29 & 4-Methyl-2-methoxyphenol (4-methylguaiacol) & 138 & 8.9 & 12.1 & 12.6 & 15.4 & 17.2 & 14.5 \\
\hline 28.28 & 4-Ethyl-2-methoxyphenol (4-ethylguaiacol) & 137 & 10.4 & 10.4 & 14.7 & 10.9 & 12.7 & 13.2 \\
\hline 28.78 & 4-Vinyl-2-methoxyphenol (4-vinylguaiacol) & 150 & 5.8 & 9.2 & 5.1 & 5.9 & 8.4 & 5.5 \\
\hline 29.19 & 4-(2-Propenyl)-2-methoxyphenol (eugenol) & 164 & 0.8 & 1.2 & 1.2 & 1.2 & 1.6 & 1.7 \\
\hline 29.32 & 4-Propyl-2-methoxyphenol (4-propylguaiacol) & 137 & 1.5 & 1.4 & 2.2 & 1.5 & 1.7 & 2.2 \\
\hline 31.31 & 4-(1-Propenyl)-2-methoxyphenol (isoeugenol) & 164 & 0.4 & 0.5 & 0.6 & 0.6 & 0.8 & 0.7 \\
\hline 31.68 & 4-(1-Propenyl)-2-methoxyphenol (isoeugenol isomer) & 164 & 1.4 & 2.2 & 2.3 & 2.4 & 3.2 & 2.5 \\
\hline 24.86 & Naphthalene & 128 & 0.6 & 1.9 & 0.9 & 0.5 & 1.7 & 1.9 \\
\hline
\end{tabular}

cheese headspace average concentrations of the main acids in samples A1, A3, A4, A5, and A6 in the same arbitrary units. It can be observed that, though the average deviations are high, indicating significant differences in the abundance of these components in the headspace of these artisan cheeses, the compounds in high or low concentrations in one sample are also in high or low concentrations in the others. Therefore, in all studied samples, phenol, guaiacol, 4-methylguaiacol, and 4-ethylguaiacol were in high proportion and trimethylphenol, propylphenol, and isoeugenol were in smaller proportions (among smoke components), and hexanoic, octanoic, and decanoic acids were the main acids in all samples.

The relative abundance of the components in relation to the total abundance affords information on the existence or absence of a common aromatic profile in several samples, with different degrees of intensity, which is determined by the absolute abundance of the components. This can be determined from the percentages of the headspace components. Table 4 shows the proportions of some of the most significant smoke components in the headspace of these cheese samples in relation to their total abundance. It can be observed that, despite the different smoking intensities, in general all of them contain similar proportions of these smoke components, showing that the smoking process is fairly homogeneous because it provides almost constant proportions of the different smoke components, with differences only in its intensity as the absolute abundances indicate. Table 5 shows the proportions of some of the main acids in the headspace of the cheese samples in relation to their total abundance. It can be observed that the proportions of acids are not as homogeneous as the proportion of smoke components in the different samples. This can be due to the fact that the lypolysis process was affected by different factors in the manufacture of these cheese samples, providing differences not only in the absolute but also in the relative abundance of acids.

This cheese was smoked with pine needles, and it may be thought that its headspace composition was affected by the composition of the vegetable matter used. It is known that the proportions of the different phenolic derivatives in smoke are clearly dependent on the lignin composition, which differs from one wood to another. For this reason, the ratio between abundances of some important phenolic derivatives or other smoke components indicated in Table 1 may be considered of interest as indicators or markers of the vegetable matter used in the smoking process.

In conclusion, in the headspace of this cheese, more than 320 components have been detected, covering a broad range of volatility, molecular weights, and nature. Among them there are acids, alcohols, esters, hydrocarbons, aldehydes, ketones, furan and pyran derivatives, terpenes and sesquiterpenes, nitrogen derivatives, phenol, guaiacol and syringol derivatives, ethers, and others. As could be expected, the richest region in components was the exterior region, where typical cheese components and a great number of pine needle smoke components were found. It is characteristic of this goat cheese that its main branched acid is 2-ethylhexanoic acid. The components coming from the smoke 
Table 5. Abundance of some main acids in the headspace of the exterior region of cheese samples A1, A2, $\mathrm{A} 3, \mathrm{~A} 4, \mathrm{~A} 5$, and A6, expressed as a percentage in relation to the total acids abundance.

\begin{tabular}{|c|c|c|c|c|c|c|c|c|}
\hline $\mathrm{RT}$ & Compound & $\mathrm{I}_{\mathrm{BP}}$ & $\mathrm{A} 1$ & $\mathrm{~A} 2$ & A3 & A4 & A5 & A6 \\
\hline 9.45 & Butyric acid & 60 & 3.9 & 17.7 & 9.3 & 9.3 & 3.9 & 10.9 \\
\hline 12.99 & Hexanoic acid & 60 & 32.2 & 55.2 & 40.7 & 41.9 & 26.5 & 26.8 \\
\hline 21.34 & 2-Ethylhexanoic acid & 73 & 1.6 & 0.0 & 0.1 & 0.0 & 0.3 & 0.3 \\
\hline 22.65 & Octanoic acid & 60 & 28.7 & 17.4 & 24.1 & 27.7 & 26.0 & 33.2 \\
\hline 25.35 & Nonanoic acid & 60 & 1.2 & 0.3 & 0.8 & 0.8 & 0.7 & 1.5 \\
\hline 28.22 & Decanoic acid & 60 & 30.7 & 9.2 & 22.7 & 19.4 & 35.5 & 25.7 \\
\hline 37.86 & Dodecanoic acid & 73 & 1.2 & 0.2 & 1.7 & 0.6 & 3.8 & 1.4 \\
\hline 43.48 & Tetradecanoic acid & 73 & 0.4 & 0.0 & 0.5 & 0.3 & 3.2 & 0.3 \\
\hline
\end{tabular}

play an important role in the flavor of this cheese, and in spite of the variability found in the smoking intensity of the different cheeses, all of them showed fairly constant values in terms of relative abundance of phenolic derivatives, which were the main smoke components detected. These relative abundances together with other smoke components could be of interest as markers of this fresh goat cheese smoked with pine needles.

\section{ACKNOWLEDGMENTS}

This work has been supported by the Comisión Interministerial de Ciencia y Tecnología, Ministerio de Ciencia y Tecnología (MCYT, AGL2000-1696 and CAL00054-C3-2), and Universidad del País Vasco (9/UPV 00101.125.13667/2003). G. Palencia thanks the Universidad del País Vasco for a predoctoral fellowship. The authors are grateful for the collaboration of the Palmero Artisans and of the Consejo Regulador of the Origin Denomination.

\section{REFERENCES}

Adamopoulos, K. G., A. M. Goula, and H. J. Petropakis. 2001. Quality control during processing of Feta cheese-NIR application. J. Food Comp. Anal. 14:431-440.

Banks, J. M., E. Y. Brechany, W. W. Christie, E. A. Hunter, and D. D. Muir. 1992. Volatile components in steam distillates of Cheddar cheese as indicator indexes of cheese maturity, flavor and odor. Food Res. Int. 25:365-373.

Barbieri, G., L. Bolzoni, M. Careri, A. Mangia, G. Parolari, S. Spagnoli, and R. Virgili. 1994. Study of the volatile fraction of Parmesan cheese. J. Agric. Food Chem. 42:1170-1176.

Bosset, J. O., and R. Gauch. 1993. Comparison of the volatile flavor compounds of six European AOC cheeses by using a new dynamic headspace GC-MS method. Int. Dairy J. 3:359-377.

Bosset, J. O., U. Butikofer, R. Gauch, and R. Sieber. 1994. Occurrence of terpenes and aliphatic hydrocarbons in Swiss Gruyere and Etivaz alpine cheese using dynamic headspace GC-MS analysis of their volatile flavour compounds. Schweiz. Milchwirtsch. Forsch. 23:37-42.

Bosset, J. O., U. Butikofer, T. Berger, and R. Gauch. 1997. Study of the volatile compounds of the Vacherin Fribourgeois and (Swiss) Vacherin Mont-d'Ór cheese varieties. Mitt. Geb. Lebensmittelunters. Hyg. 88:233-258.

Careri, M., P. Manini, S. Spagnoli, G. Barbieri, and L. Bolzoni. 1994. Simultaneous distillation-extraction and dynamic headspace methods in the gas chromatographic analysis of Parmesan cheese volatiles. Chromatographia 38:386-394.
Chin, H. W., R. A. Bernhard, and M. Rosenberg. 1996. Solid phase microextraction for cheese volatile compound analysis. J. Food Sci. 61:1118-1122, 1128

Dirinck, P., and A. De Winne. 1999. Flavor characterisation and classification of cheeses by gas chromatographic-mass spectrometric profiling. J. Chromatogr. A 847:203-208.

Dufour, J. P., P. Delbecq, and L. Perez. 2001. Solid-phase microextraction combined with gas chromatography-olfactometry for analysis of cheese aroma. ACS Symp. Ser. 782:123-137.

Dumont, J. P., J. Adda, and P. Rousseaux. 1981. Example of flavor variation within the same type of cheese: Gruyere de Comte. Lebensm.-Wiss. Technol. 14:198-202.

Gao, S., D. H. Oh, J. R. Broadbent, M. E. Johnson, B. C. Weimer, and J. L. Steele. 1997. Aromatic amino acid catabolism by lactococci. Lait 77:371-381.

Guichard, E., J. L. Berdague, and R. Grappin. 1987. Ripening and quality of Gruyere of Comte cheese. Change in the amounts of volatile compounds in relation to season of manufacture and ripening conditions. Lait 67:319-337.

Guillén, M. D., and B. Abascal. 2002. Study of the volatile fraction of cheese smoked by means of smoke flavourings, using solid phase microextraction followed by GC/MS. Page 78 in 10 as Jornadas de Análisis Instrumental, Barcelona, Spain.

Guillén, M. D., and M. C. Errecalde. 2002. Volatile components of raw and smoked black bream (Brama raii) and rainbow trout (Oncorhynchus mykiss) studied by means of solid phase microextraction and gas chromatography/mass spectrometry. J. Sci. Food Agric. 82:945-952.

Guillén, M. D., and M. L. Ibargoitia. 1996. Aqueous liquid smoke flavoring preparations from vine shoots and beech wood. J. Sci. Food Agric. 72:104-110.

Guillén, M. D., and M. L. Ibargoitia. 1998. New components with potential antioxidant and organoleptic properties, detected for the first time in liquid smoke flavoring preparations. J. Agric. Food Chem. 46:1276-1285.

Guillén, M. D., and M. J. Manzanos. 1999. Extractable components of the aerial parts of Salvia lavandulifolia and the composition of the liquid smoke flavoring obtained from them. J. Agric. Food Chem. 47:3016-3027.

Guillén, M. D., M. J. Manzanos, and M. L. Ibargoitia. 2001. Carbohydrate and nitrogenated compounds in liquid smoke flavorings. J. Agric. Food Chem. 49:463-468.

Guillén, M. D., M. J. Manzanos, and L. Zabala. 1995. Study of a commercial liquid smoke flavouring by means of GC/MS and FTIR. J. Agric. Food Chem. 43:463-468.

Jaillais, B., V. Bertrand, and J. Auger. 1999. Cryo-trapping/SPME/ GC analysis of cheese aroma. Talanta 48:747-753.

Kemmer, H., M. Dehnhard, and R. Claus. 1997. Screening of indoles in cheese. Z. Lebensm.-Unters.-Forsch. A. 205:433-436.

Kim, K., T. Kurata, and M. Fujimaki. 1974. Smoke flavor. II. Identification of flavor constituents in carbonyl, noncarbonyl neutral, and basic fractions of aqueous smoke condensates. Agric. Biol. Chem. 38:53-63.

Kubícková, J., and W. Grosch. 1997. Evaluation of potent odorants of Camembert cheese by dilution and concentration techniques. Int. Dairy J. 7:65-70. 
Lapp, M. S., and R. E. Von. 1982. Chemosystematic studies in the genus Pinus. IV. Leaf oil composition and geographic variation in jack pine of eastern North America. Can. J. Bot. 60:2762-2769.

Larrayoz, P., M. Addis, R. Gauch, and J. O. Bosset. 2001. Comparison of dynamic headspace and simultaneous distillation extraction techniques used for the analysis of the volatile components in three European PDO ewes' milk cheeses. Int. Dairy J. 11:911-926.

Larsen, T. O. 1999. Volatile flavor production by Penicillium caseifulvum. Int. Dairy J. 8:883-887.

Lecanu, L., V. Ducruet, C. Jouquand, J. J. Gratadoux, and A. Feigenbaum. 2002. Optimization of headspace solid-phase microextraction (SPME) for the odor analysis of surface-ripened cheese. J. Agric. Food Chem. 50:3810-3817.

Lee, J. H., R. Diono, G. Y. Kim, and D. B. Min. 2003. Optimization of solid phase microextraction analysis for the headspace volatile compounds of parmesan cheese. J. Agric. Food Chem. 51:11361140 .

Liebich, H. M., D. R. Douglas, E. Bayer, and A. Zlatkis. 1970a. Volatile flavor components of Cheddar cheese. J. Chromatogr. Sci. $8: 355-359$

Liebich, H. M., D. R. Douglas, E. Bayer, and A. Zlatkis. 1970b. Volatile flavour components of Cheddar cheese. Pages 219-225 in Proc. 6th Int. Symp. Advan. Chromatogr. University of Houston, Houston, TX.

Maga, J. A. 1988. Smoke in Food Processing, CRC Press, Boca Raton, FL.

Marculescu, A., and M. Gleizes. 2002. Composition of volatile substances in conifer species from the montane zone. 3. Pine (Pinus silvestris L.) leaves. Rev. Chim. 53:185-189.

Martelli, A. 1989. Volatile components of Gorgonzola cheese flavor. La Rivista della Societa Italiana di Scienza dell'Alimentazione. 18:251-262.

Martinez-Castro, I., J. Sanz, L. Amigo, M. Ramos, and P. MartinAlvarez. 1991. Volatile components of Manchego cheese. J. Dairy Res. 58:239-246.

Moio, L., and F. Addeo. 1998. Grana Padano cheese aroma. J. Dairy Res. 65:317-333.

Moio, L., J. Dekimpe, P. X. Etievant, and F. Addeo. 1993. Volatile flavor compounds of water buffalo Mozzarella cheese. Ital. J. Food Sci. 5:57-68.

Moio, L., P. Piombino, and F. Addeo. 2000. Odour-impact compounds of Gorgonzola cheese. J. Dairy Res. 67:273-285.

Molimard, P., and H. E. Spinnler. 1996. Review: Compounds involved in the flavor of surface mold-ripened cheeses: origins and properties. J. Dairy Sci. 79:169-184.

Muir, D. D., E. A. Hunter, and J. M. Banks. 1997. Aroma of cheese. Part 2. Contribution of aroma to the flavor of Cheddar cheese. Milchwissenschaft 52:85-88.
Orden de 31 de agosto de 2001 por la que se ratifica el Reglamento de la Denominación de Origen "Queso Palmero" y de su Consejo Regulador. B.O.E. No. 218: 11/9/01:34210-34217.

Overstrom, H., J. Reigo, and S. Borgstrom. 1972. Preliminary study concerning formation of benzoic acid in cheese. Milchwissenschaft 27:705-708.

Papadopoulou, K., and P. Koukos. 1996. Variation of the essential oils of the leaves, twigs and cones of Balkan pine (Pinus peuce Grisebach) grown in Greece. J. Essent. Oil Res. 8:499-502.

Parliment, T. H., M. G. Kolor, and D. J. Rizzo. 1982. Volatile components of Limburger cheese. J. Agric. Food Chem. 30:1006-1008.

Rychlik, M., and J. O. Bosset. 2001. Flavour and off-flavour compounds of Swiss Gruyere cheese. Evaluation of potent odorants. Int. Dairy J. 11:895-901.

Sabio, E., and M. C. Vidal-Aragón. 1996. Analysis of the volatile fraction of Ibores cheese. Alimentaria 278:101-103.

Salles, C., N. Sommerer, C. Septier, S. Issanchou, C. Chabanet, A Garem, and J. L. Le Quere. 2002. Goat cheese flavor: Sensory evaluation of branched-chain fatty acids and small peptides. J. Food Sci. 67:835-841.

Sieber, R., U. Buetikofer, and J. O. Bosset. 1995. Benzoic acid as a natural compound in cultured dairy products and cheese. J. Reprod. Med. 40:227-246.

Sloot, D., and P. D. Harkes. 1975. Volatile trace components in Gouda cheese. J. Agric. Food Chem. 23:356-357.

Sorensen, J., and C. Benfeldt. 2001. Comparison of ripening characteristics of Danbo cheeses from two dairies. Int. Dairy J. 11:355-362.

Sunesen, L. O., P. Lund, J. Sorensen, and G. Holmer. 2002. Development of volatile compounds in processed cheese during storage. Lebensm.-Wiss. Technol. 35:128-134.

Tavaria, F. K., S. Dahl, F. J. Carballo, and F. X. Malcata. 2002. Amino acid catabolism and generation of volatiles by lactic acid bacteria. J. Dairy Sci. 85:2462-2470.

Thierry, A., M. B. Maillard, and J. L. Le Quéré. 1999. Dynamic headspace analysis of Emmental aqueous phase as a method to quantify changes in volatile flavour compounds during ripening. Int. Dairy J. 9:453-463.

Valero, E., J. Sanz, and I. Martinez-Castro. 2001. Direct thermal desorption in the analysis of cheese volatiles by gas chromatography and gas chromatography-mass spectrometry: comparison with simultaneous distillation-extraction and dynamic headspace. J. Chromatogr. Sci. 39:222-228.

Watkins, P. J., Z. Shen, and C. Wijesundera. 2002. Determination of volatile flavour compounds in cheese by SPME and GC/MS. Aust. J. Dairy Technol. 57:70. 